\title{
Rapid evolution and copy number variation of primate RHOXF2, an X-linked homeobox gene involved in male reproduction and possibly brain function
}

Ao-lei Niu ${ }^{1,2+}$, Yin-qiu Wang ${ }^{1,3+}$, Hui Zhang ${ }^{1 \dagger}$, Cheng-hong Liao ${ }^{1}$, Jin-kai Wang ${ }^{1}$, Rui Zhang ${ }^{1}$, Jun Che ${ }^{1}$ and Bing Su${ }^{1 *}$

\begin{abstract}
Background: Homeobox genes are the key regulators during development, and they are in general highly conserved with only a few reported cases of rapid evolution. RHOXF2 is an X-linked homeobox gene in primates. It is highly expressed in the testicle and may play an important role in spermatogenesis. As male reproductive system is often the target of natural and/or sexual selection during evolution, in this study, we aim to dissect the pattern of molecular evolution of RHOXF2 in primates and its potential functional consequence.

Results: We studied sequences and copy number variation of RHOXF2 in humans and 16 nonhuman primate species as well as the expression patterns in human, chimpanzee, white-browed gibbon and rhesus macaque. The gene copy number analysis showed that there had been parallel gene duplications/losses in multiple primate lineages. Our evidence suggests that 11 nonhuman primate species have one RHOXF2 copy, and two copies are present in humans and four Old World monkey species, and at least 6 copies in chimpanzees. Further analysis indicated that the gene duplications in primates had likely been mediated by endogenous retrovirus (ERV) sequences flanking the gene regions. In striking contrast to non-human primates, humans appear to have homogenized their two RHOXF2 copies by the ERV-mediated non-allelic recombination mechanism. Coding sequence and phylogenetic analysis suggested multi-lineage strong positive selection on RHOXF2 during primate evolution, especially during the origins of humans and chimpanzees. All the 8 coding region polymorphic sites in human populations are non-synonymous, implying on-going selection. Gene expression analysis demonstrated that besides the preferential expression in the reproductive system, RHOXF2 is also expressed in the brain. The quantitative data suggests expression pattern divergence among primate species.
\end{abstract}

Conclusions: RHOXF2 is a fast-evolving homeobox gene in primates. The rapid evolution and copy number changes of RHOXF2 had been driven by Darwinian positive selection acting on the male reproductive system and possibly also on the central nervous system, which sheds light on understanding the role of homeobox genes in adaptive evolution.

\footnotetext{
* Correspondence: sub@mail.kiz.ac.cn

† Contributed equally

${ }^{1}$ State Key Laboratory of Genetic Resources and Evolution, Kunming Institute of Zoology and Kunming Primate Research Center, Chinese Academy of

Sciences, Kunming, Yunnan 650223, China

Full list of author information is available at the end of the article
} 


\section{Background}

Homeobox genes encode homeobox proteins that play a crucial role in various developmental processes as transcription factors. A key feature of homeobox proteins is the homeodomain, a 60-amino-acid helix-turn-helix DNA-binding domain [1]. Due to their functional importance during development, most of the homeobox genes (especially the homeodomain) are highly conserved at sequence level [1-3]. There have been only a few published examples of rapid evolution of homeobox genes, such as $\mathrm{OdsH}$ in flies [4], Hox genes in nematodes [5,6], the Rhox5 cluster genes in rodents [7-12], and TGIFLX and $E S X 1$ in primates $[13,14]$. Here we report a novel case of rapid evolution as well as copy number variation $(\mathrm{CNV})$ of an X-linked reproductive homeobox family gene, member 2 (RHOXF2) in primates. This homeobox gene is involved in spermatogenesis and may also play a role in brain function.

RHOXF2, selectively expressed in the testis, was initially identified as a member of the PEPP subfamily [15]. The human RHOXF2 gene is also named as testis homeobox gene 1 (THG1) or human paired-like homeobox protein ( $h P E P P 2)$. It is located on Xq24 and contains 4 exons encoding a 288 -amino-acids protein with two functional domains, the homeodomain and the proline-rich domain (figure 1a)[15]. In humans, there are two copies of the RHOXF2 gene on Xq24 in a head-to-head orientation, i.e. RHOXF2 and RHOXF2b [15]. The Rhox (reproductive homeobox on the $\mathrm{X}$ chromosome) cluster genes in rodents have been considered to be orthologs of human RHOXF2 [15]. Recent studies have shown that the human RHOXF2 protein is functionally similar to the rodent Rhox 5, the founding member of the Rhox cluster, expressed in the Sertoli cells of the testis and promoting survival and differentiation of the adjacent male germ cells during spermatogenesis $[8,16-18]$. Similar to the Rhox cluster genes in rodents, the human RHOXF2 can downregulate the expression of $U n c 5 c$ and Pltp, and up-regulate Gdap1 expression in the Sertoli-cell pathway promoting germ cell survival $[16,18]$. Interestingly, all three downstream genes directly regulated by RHOXF2 in the testis also play important roles in the nervous system. In the brain, $U n c 5 c$ is a receptor of netrin-1, which is important for axonal guidance, neuron migration and proliferation $[19,20]$. Pltp is an important modulator of the signal transduction pathways in the human neurons, and is likely involved in neurodegenerative and inflammatory brain diseases [21,22]. Gdap1 is involved in a signal transduction pathway in neuronal development, and is responsible for

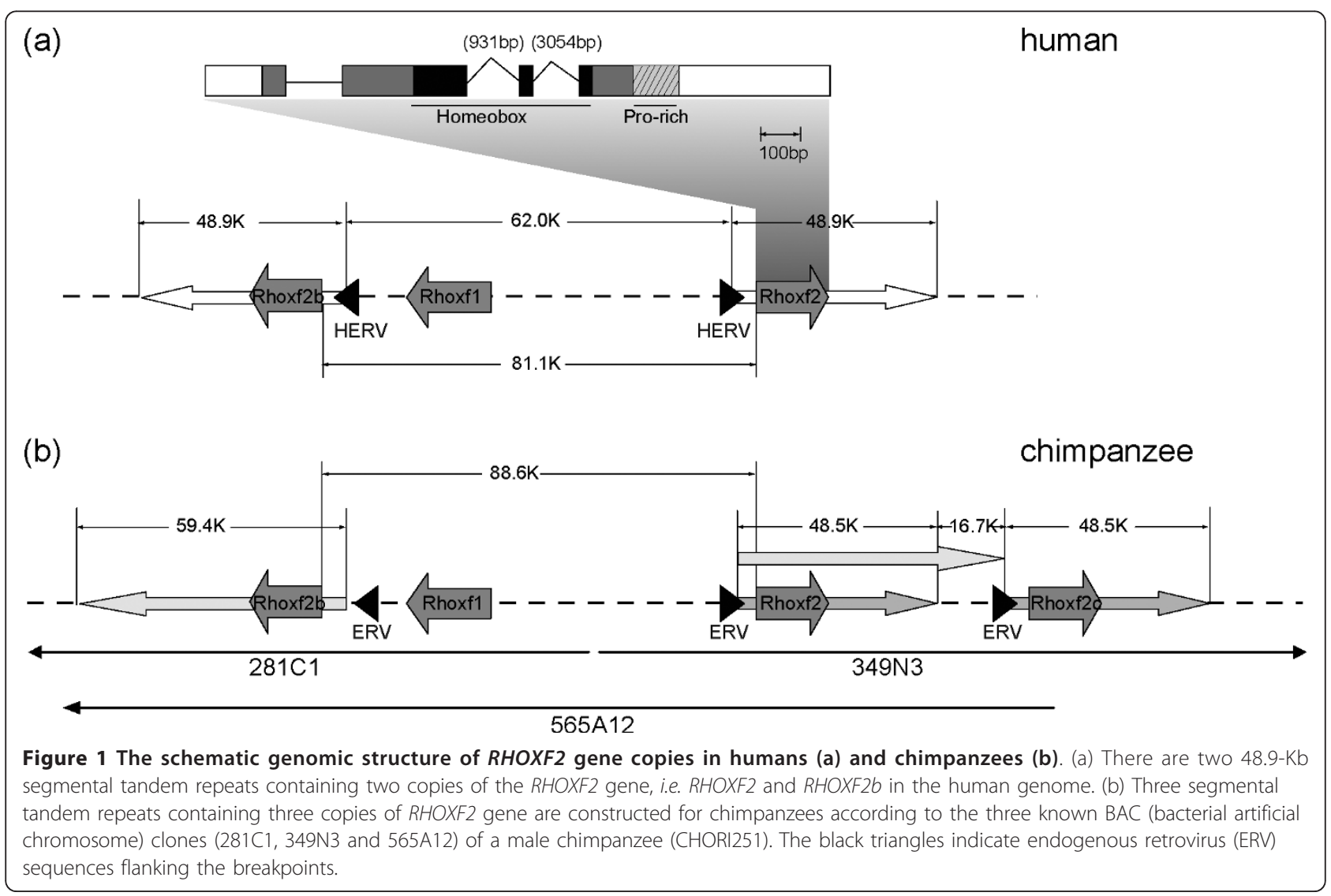


various Charcot-Marie-Tooth diseases, the most common peripheral neuropathy [23,24].

Due to the function of RHOXF2 in spermatogenesis and possibly in the central nervous system, we studied the evolutionary pattern of this homeobox gene in primates, and we observed frequent gene duplications/losses and rapid protein sequence changes. We also performed expression pattern analysis in multiple primate species, and examined between-species and between-paralogs expression divergences. Our evidence suggests that the rapid evolution of $R H O X F 2$ at both the sequence and expression levels is likely to have been caused by selection on the male reproductive system and possibly also on the central nervous system.

\section{Results}

\section{RHOXF2 copy number variation in primates}

In humans, there are two RHOXF2 gene copies on Xq24 in a head-to-head orientation, RHOXF2 and RHOXF2b (figure 1a) [15]. We sequenced the entire coding sequences (867bp) and about 600bp adjacent noncoding regions (including the entire 185bp intron-1 and the flanking sequences of the exons) in 111 human individuals (including African, European, Melanesian and East Asian; 83 males and 28 females). There are 14 individuals (12 males and 2 females) showing no heterozygous sites in the entire sequenced region. This suggests that these individuals either have two identical or only a single copy of the RHOXF2 gene located on the $\mathrm{X}$ chromosome.

In the reference human genome, there are two $48.9-\mathrm{Kb}$ segmental tandem repeats containing the two RHOXF2 copies (figure 1a). We sequenced the genomic regions covering the breakpoints of the two segmental repeats in 30 human genomic DNA samples (including all individuals without heterozygous site and all individuals subject to qPCR). The data indicated that the breakpoint sequences exist in all individuals (including 14 individuals without heterozygous sites), implying that they all have two copies. This result was further confirmed by genomic DNA realtime quantitative PCR of 9 individuals with heterozygous sites ( 4 males and 5 females) and 8 individuals without heterozygous sites ( 7 males and 1 female) (see additional file 1). Using TKTL1, an X-linked single copy gene as a control, we found these samples are no difference in $R H O X F 2$ genomic DNA quantity ( $\mathrm{P}>0.05$, T test). Collectively, our data demonstrate that the two copies of RHOXF2 are fixed in contemporary humans.

To see whether the two-copy structure is conserved in nonhuman primates, we first conducted PCR-based sequencing of the entire coding region of the 16 nonhuman primate species (table 1). A single copy X-linked gene would have no heterozygous site in males, therefore heterozygous sites in males suggest more than one gene copy. Our results showed that three species (chimpanzees, pig-tailed macaques and rhesus macaques) have heterozygous sites in males, suggesting more than one copy in them. The two leaf monkey species (all females) also have heterozygous sites. Since a single copy X-linked gene would also have heterozygous sites in females due to within-copy polymorphisms, their copy numbers were then determined by genomic DNA qPCR. The other 11 nonhuman primate species do not exhibit any heterozygous sites, implying either a single copy or two/multiple identical copies, which was then tested by genomic DNA qPCR. According to the genome database, there are two copies in the white-tufted-ear marmoset (one intact copy and one incomplete copy due to low quality of the sequence assembly) (http://genome.wustl.edu).

To identify the RHOXF2 gene sequences of individual copies, we cloned and sequenced the PCR products of the five species with heterozygous sites. In pig-tailed macaques and rhesus macaques (all males), we identified two distinct sequences in both species, implying the presence of two copies. In rhesus macaques, there are 6 fixed single nucleotide differences between the two copies and all of them are non-synonymous substitutions located in the proline-rich domain (see additional file 2). We then sequenced 20 rhesus macaque individuals (including both males and females). Interestingly, all 20 rhesus macaques possessed the same two copy sequences without any within-copy polymorphic sites, implying strong functional restriction. The fixed sequence divergence between the two rhesus macaque copies is totally different from the pattern seen in humans, and the two human copies do not exhibit any fixed substitutions.

The grey leaf monkey and the black leaf monkey (all females) also possess two distinct sequences with 16 (14 non-synonymous and 2 synonymous substitutions) and 15 (13 non-synonymous and 2 synonymous substitutions) substitutions respectively. The majority (14/16 for grey leaf monkey, 14/15 for black leaf monkey) of the substitutions are shared between the two species, suggesting that the substitutions are between-copy divergences instead of within-copy polymorphisms. Therefore, grey leaf and black leaf monkeys likely possess two copies of RHOXF2 (see additional file 2). Phylogenetic analysis revealed that gene duplication occurred before the two species diverged (figure 2).

The results of genomic DNA qPCR indicated that the RHOXF2 genomic DNA quantities of rhesus macaques and pig-tailed macaques are about twice those of other macaque species with no heterozygous sites (figure 3a). The same result was also seen for leaf monkeys when compared with the Yunnan snub-nosed monkey (no heterozygous sites) (figure $3 \mathrm{~b}$ ). The data further supports that rhesus macaques, pig-tailed macaques, grey leaf and black 
Table 1 Summary of the primate species examined for RHOXF2 and their sequence divergences from human

\begin{tabular}{|c|c|c|c|c|c|c|c|c|}
\hline Lineage & Common name & Abbr. & Scientific name & No. of Individuals & Sex & Protein divergence from human & $\mathrm{Ka} / \mathrm{Ks}$ & Diverged time from human (my) \\
\hline Human & Human & HUM & Homo sapiens & $111 / 4 / 7 / 1^{*}$ & / & I & I & I \\
\hline Great Ape & Chimpanzee & $\mathrm{CHP}$ & Pan troglodytes & $6 / 2 / 2 / 1^{*}$ & / & $5.7 \%$ & 3.44 & 5 \\
\hline Great Ape & Gorilla & GOR & Gorilla gorilla & 1 & M & $5.5 \%$ & 0.86 & 7 \\
\hline Great Ape & Orangutan & ORA & Pongo pygmaeus & 1 & M & $11.3 \%$ & 1.14 & 14 \\
\hline Lesser Ape & Siamang & SIA & Symphalangus syndactylus & 1 & M & $17.5 \%$ & 1.69 & 18 \\
\hline Lesser Ape & White-browed gibbon & WBG & Hylobates hoolock & $1 / 0 / 0 / 1^{*}$ & M & $17.9 \%$ & 1.65 & 18 \\
\hline Lesser Ape & White-cheeked gibbon & WCG & Hylobates leucogenys & 1 & $\mathrm{~F}$ & $18.3 \%$ & 1.57 & 18 \\
\hline Old World Monkey & Grey leaf monkey & GLM & Trachypithecus phayrei & 1 & $\mathrm{~F}$ & $23.5 \%$ & 1.21 & 25 \\
\hline Old World Monkey & Black leaf monkey & BLM & Trachypithecus francoisi & 1 & $\mathrm{~F}$ & $22.4 \%$ & 1.11 & 25 \\
\hline Old World Monkey & Yunnan golden monkey & YGM & Rhinopithecus bieti & 1 & $\mathrm{~F}$ & $23.0 \%$ & 1.43 & 25 \\
\hline Old World Monkey & Douc langur & $\mathrm{DL}$ & Pygathrix nemaeus & 1 & M & $21.7 \%$ & 1.22 & 25 \\
\hline Old World Monkey & Red guenon & RG & Erythrocebus patas & 1 & $\mathrm{~F}$ & $23.9 \%$ & 1.15 & 25 \\
\hline Old World Monkey & Stump-tailed macaque & STM & Macaca arctoides & 1 & $\mathrm{~F}$ & $21.1 \%$ & 0.93 & 25 \\
\hline Old World Monkey & Pere David's macaque & PDM & Macaca thibetana & 1 & $\mathrm{~F}$ & $21.1 \%$ & 0.98 & 25 \\
\hline Old World Monkey & Assam macaque & AM & Macaca assamensis & 1 & M & $21.1 \%$ & 0.98 & 25 \\
\hline Old World Monkey & Pig-tailed macaque & PTM & Macaca nemestrina & 1 & M & $21.1 \%$ & 0.99 & 25 \\
\hline Old World Monkey & Rhesus macaque & RM & Macaca mulatta & $20 / 2 / 2 / 3^{*}$ & / & $21.1 \%$ & 0.99 & 25 \\
\hline New World Monkey & White-Tufted-Ear Marmoset & MAR & Callithrix jacchus & Database & $\mathrm{F}$ & $53.4 \%$ & 1.12 & 40 \\
\hline
\end{tabular}

* The number of individuals for genomic DNA analysis, brain CDNA expression analysis, testis CDNA expression analysis and multi-tissue expression analysis, respectively. 


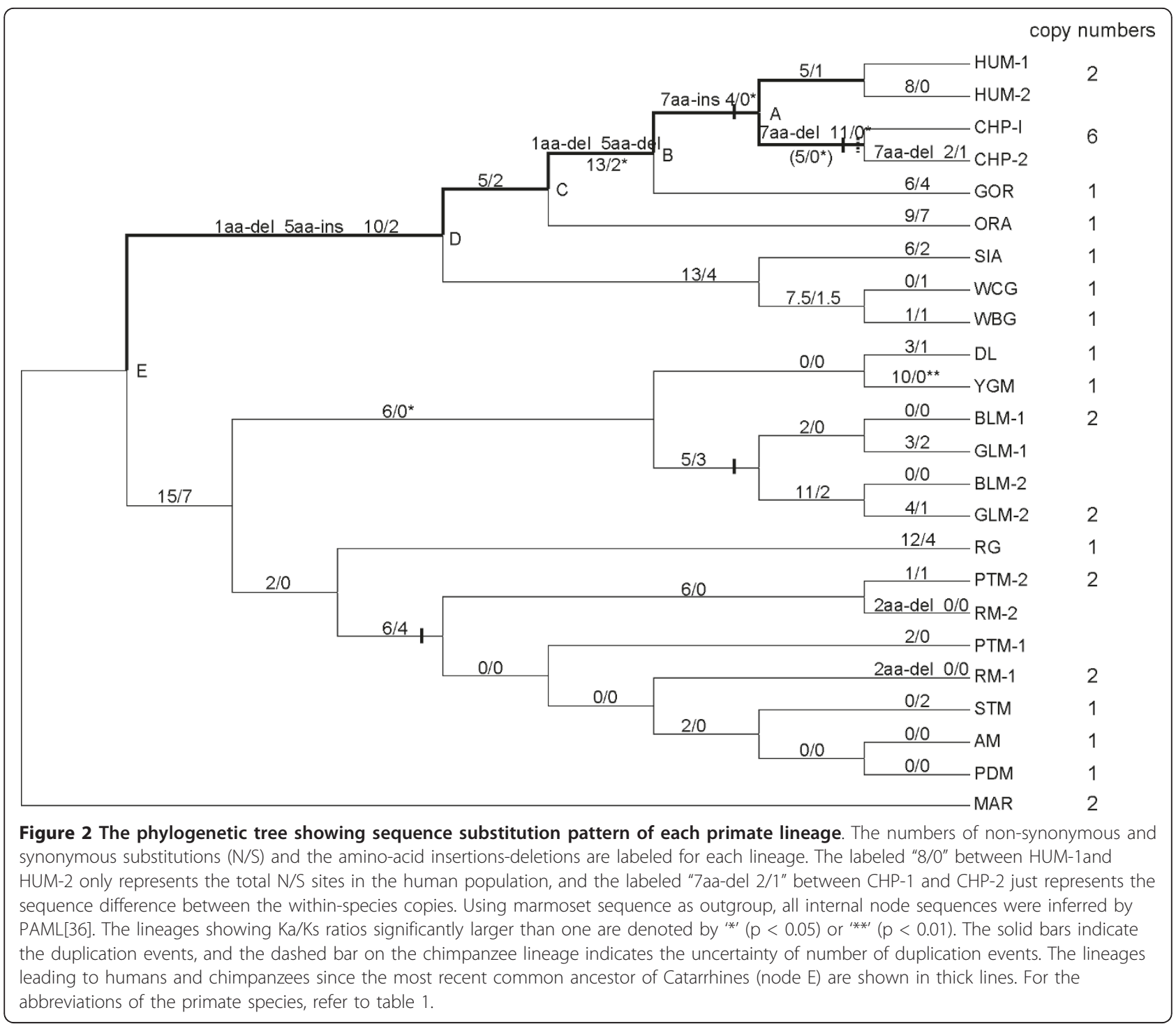

leaf monkeys possess two RHOXF2 gene copies, and there is only one copy in the nonhuman primate species without heterozygous sites.

In chimpanzees, we identified at least 4 different sequences by screening the 26 cDNA clones from the testicle of a male individual, suggesting multiple copies in its genome (see additional file 2 and additional file 3). To explore the detailed genomic structure of RHOXF2 gene copies in the chimpanzee, we screened the BAC (bacterial artificial chromosome) library of a male chimpanzee (CHORI251). We obtained 7 positive BAC clones containing the RHOXF2 gene sequence, including 281C1, 349N3, 565A12, 602H9, 792F3, 792G12 and 834E8. For three of them $(281 \mathrm{C} 1,349 \mathrm{~N} 3$ and 565A12), sequences are available in the NCBI database [GenBank: AC145687, AC142344 and $\mathrm{AC} 183597]$. Our BAC-end and breakpoint-region resequencing confirmed the sequence alignments of the contig (315 kb) containing the three NCBI BAC clones, and 3 copies of RHOXF2 gene are located within this contig (figure 1b). Two of the three copies are orthologs of the two human copies according to the synteny of this genomic region. We then partially sequenced the other 4 BAC clones, and we found that 792F3 showed sequence differences from the 3 known BAC clones, an indication of at least one extra copy in chimpanzees. Finally, we performed genomic DNA qPCR and the result showed that the copy number in chimpanzees is about 3 times (3.03 \pm 0.65) larger than in humans, suggesting 5-7 copies in chimpanzees. Combining the data from the BAC clones and the cDNA clones from testicle and brain samples (see additional file 2 and additional file 3), there are at least 6 copies in the chimpanzee genome.

To reveal the genomic locations of all these copies in chimpanzees, using BAC clone $281 \mathrm{C} 1$ as the probe 


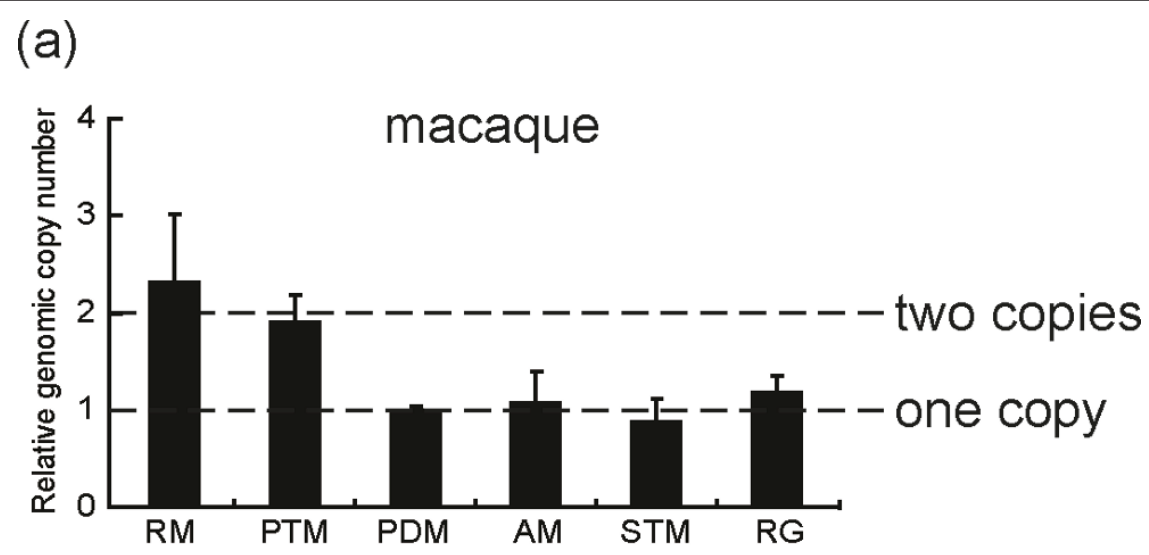

(b)

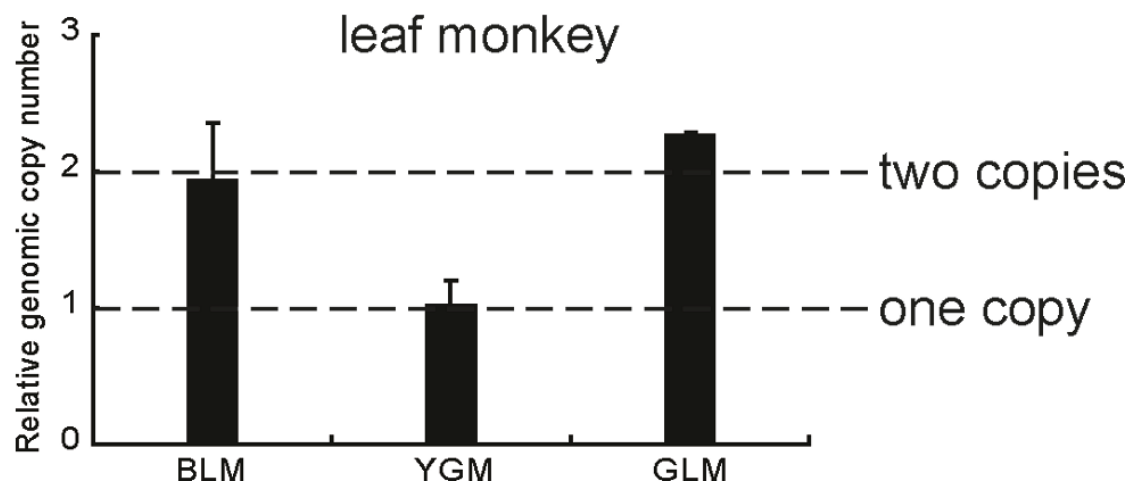

Figure 3 The result of genomic DNA qPCR in macaques (a) and leaf monkeys (b). (a) RM and PTM showed about 2 fold of RHOXF2 gene genomic DNA compared to the other macaques. (b) BLM and GLM showed about 2 fold of RHOXF2 gene genomic DNA compared to YGM. The single copy X-linked gene, transketolase-like 1 (TKTL1) is the reference gene. For the abbreviations of the tested primate species, refer to table 1.

containing a complete copy of RHOXF2, we performed chromosome fluorescence in situ hybridization (FISH). The results indicated that all signals are located in the long arm of X chromosome (see additional file 4), suggesting that all the copies are possibly tandem duplications on Xq24, which was partially reflected by the determined genomic structure of the three copies in chimpanzees (figure 1b).

Additionally, we sequenced the entire RHOXF2 gene coding region of six chimpanzee individuals (genomic DNA samples). We observed in-del polymorphisms in exon 2 of three chimpanzees, implying that copy number variation might exist in chimpanzees. We also performed cDNA sequencing of testicle samples in chimpanzees, and there are frame-shifting in-del polymorphisms, suggesting that there are non-functional copies (pseudogenes) (see additional file 2).

Endogenous retrovirus (ERV) sequences and copy number variation

In humans, based on the sequences of male individuals, a total of 12 haplotypes were inferred using PHASE [25].
Interestingly, we did not observe any fixed substitutions between the two human copies. The haplotype pattern indicates that almost all the substitutions are shared by the two copies, suggesting frequent non-allelic homologous recombination between them. Further investigation showed that there are two human endogenous retrovirus (HERV) sequences located at the breakpoint region of the two copies (figure 1). They are ERV3-like sequences, similar to HERV15Yq1 and HERV15Yq2 located at Yq11 in the human genome [26]. It has been shown that the intra-chromosomal homologous recombination between HERV15Yq1 and HERV15Yq2 can mediate duplications and deletions of the azoospermia factor A (AZFa) region on the human $Y$ chromosome, resulting in male infertility [27-29]. We used the HERV15 LTR 787-bp segment sequence as a reference to acquire the HERV sequences located at Xq24 from genome database [30]. It turned out that there is almost no difference (1/783bp) between the two HERV sequences flanking RHOXF2 (see additional file 5). Thus, the flanking locations of the two HERV sequences and their high sequence similarity suggest that the HERVs may mediate frequent non-allelic 
recombinations of the two human copies, similar to the mechanism known for the AZFa region [27,28,30]. In the database of Genomic Variants and 1000-Genomes, low frequency copy number variations (CNVs) were observed in humans covering the $R H O X F 2$ gene region (http://projects.tcag.ca and http://browser.1000genomes.org) $[31,32]$, supporting the proposed non-allelic recombinations mediated by the HERVs.

Further analysis indicated that there are also ERV sequences near RHOXF2 in the four nonhuman primate species as their whole-genome sequences available for study (chimpanzee, gorilla, orangutan and rhesus macaque) (see additional file 5). Therefore, it is possible that endogenous retrovirus sequences are the key elements causing non-allelic recombinations, resulting in copy number variation among primates. In the marmoset, we found only one ERV sequence near RHOXF2, which is likely due to the insufficient coverage of this genomic region.

Compared with the human sequences (1/783), the orthologous nonhuman primate ERV sequences are highly diverged (20/780 in chimpanzee, 90/776 in gorilla, 57/767 in orangutan and 109/775 in rhesus macaque) (see additional file 5). This implies that frequent non-allelic recombinations might not have occurred in nonhuman primates involving two RHOXF2 copies (rhesus macaque, pig-tailed macaque, grey leaf and black leaf monkey). For example, in the rhesus macaque, we identified only two RHOXF2 coding-region haplotypes with six fixed between-copy substitutions (see additional file 2). This is consistent with previous computational analysis as well as data for Arabidopsis, which proposed that the recombination frequency decreases very rapidly with the increase of sequence divergence $[33,34]$. In chimpanzee, there are more than two ERV sequences (figure $1 \mathrm{~b}$ ), resulting in a more complicated pattern requiring further illumination through future detailed sequence analysis.

Additionally, for the 11 primate species with no heterozygous site, the distinct sequence divergence between the flanking ERVs (in gorilla and orangutan) is consistent with our proposal of one RHOXF2 copy in these species, as determined by genomic DNA qPCR (figure 3).

\section{Multi-lineage positive selection on primates}

We conducted coding sequence comparison among the primate species as well as phylogenetic-tree-based analysis for the molecular signatures of selection. To simplify the phylogenetic analysis, we generated two sequences by randomizing the SNPs of humans and chimpanzees respectively to represent their RHOXF2 coding sequences. Different combinations of randomizing the SNPs gave rise to the same results, and it remains unaffected under the most conservative scenario in which the sequence was reconstructed in each species without any non-synonymous changes (see additional file 6). All of the sequences from the other primates have distinctive haplotype sequences confirmed by clone sequencing. The intact copy of the marmoset sequence was used as an out-group.

The aligned protein sequences revealed high substitution rates (as well as frequent in-dels) for RHOXF2 in Catarrhini primates (see additional file 7) We found that $69.8 \%(206 / 295)$ of sites have become variable since the most recent ancestor of Catarrhine. In other words, only $30.2 \%$ of amino acids are identical among the 17 primate species, an indication of rapid evolution. Besides amino acid changes, there are also multiple deletions/ insertions of short amino acid fragments, especially along the lineages to humans and chimpanzees (figure 2). Notably, the fixed protein sequence divergence between human and chimpanzee is $5.7 \%(16 / 281)$, which is much higher than the genome average (1.34\%) [35].

The comparison of non-synonymous (Ka) and synonymous (Ks) nucleotide distances between gene sequences can detect selection acting on a gene. A high $\mathrm{Ka} / \mathrm{Ks}$ ratio $(>1)$ indicates positive selection, whereas a lower $\mathrm{Ka} / \mathrm{Ks}$ ratio indicates negative selection $(<1)$. The Ka versus Ks ratios for all species indicated high values $(\mathrm{Ka} / \mathrm{Ks}>1)$ in 222 out of the 253 pairs $(87.7 \%)$ (figure 4 , see additional file 8), an implication of deviation from the expectation of neutrality $(\mathrm{Ka} / \mathrm{Ks}=1)$ and strong positive selection on RHOXF2 during primate evolution. The signal of positive selection in primates was confirmed by comparing Model $2 a$ (selection) and Model $1 a$ (neutral) using the maximum-likelihood method $(2 \Delta \mathrm{LnL}=31.88, \mathrm{P}=0.000000194)$ [36]. We also examined the detailed substitution pattern of each primate

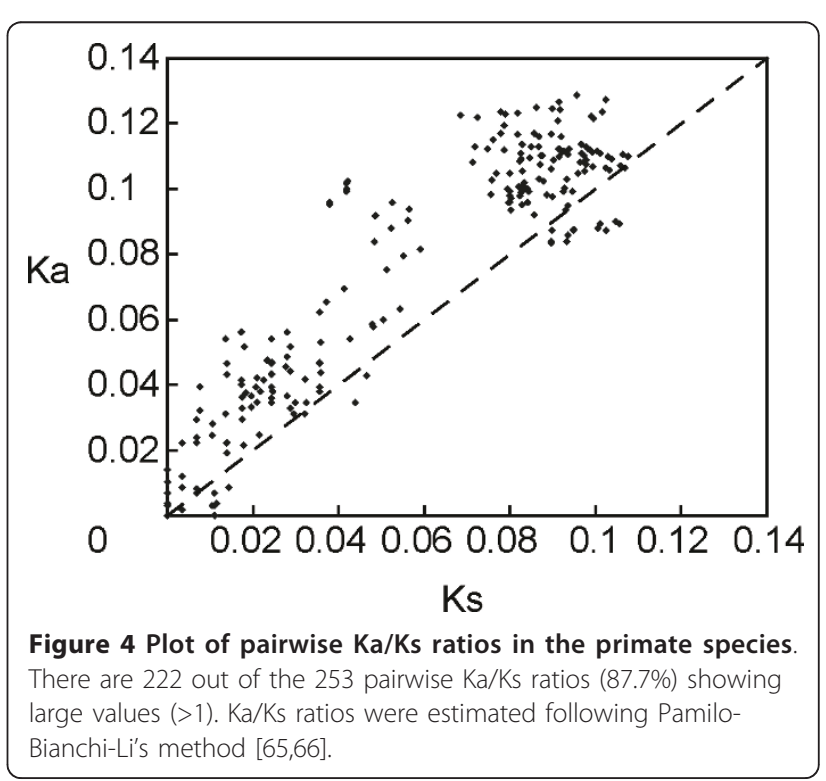


lineage in the phylogenetic tree (figure 2). The $\mathrm{Ka} / \mathrm{Ks}$ ratios of many primate lineages are larger than one, and some are statistically significant, especially the lineages leading to humans and chimpanzees, and the lineage to the Yunnan snub-nosed monkey (figure 2) [37,38].

Notably, all of the $\mathrm{Ka} / \mathrm{Ks}$ ratios for the lineages leading to humans and chimpanzees since the most recent common ancestor of Catarrhines are larger than 1 (thick lines in figure 2). The likelihood ratio test (modified model A test) indicated that these lineages have a significantly larger $\omega(d \mathrm{~N} / d \mathrm{~S})$ value $(>1)(2 \Delta \mathrm{LnL}=4.23, \mathrm{P}<$ $0.05)$, suggesting strong positive selection during the evolution of humans and chimpanzees (table 2). In comparison, another Rhox family member RHOXF1, located in the same genomic region (figure 1a), evolved much more slowly than RHOXF2 (table 2).

In the 111 human individuals tested, we observed eight sequence polymorphisms (SNPs) and all of them are nonsynonymous substitutions (83A/T, 93N/D, 151R/C, 151R/ H, 176L/F, 209Q/H, 235G/D and 286 P/L). Surprisingly, three of them $(151 \mathrm{R} / \mathrm{C}, 151 \mathrm{R} / \mathrm{H}$ and $176 \mathrm{~L} / \mathrm{F})$ are located in the homeodomain (table 3 ). No synonymous substitutions were observed in the entire coding region of RHOXF2, an indication of on-going positive selection on current human populations. In the chimpanzee lineage (node A to chimpanzee ancestor), there are 5 non-synonymous substitutions while a 7-aa deletion without any synonymous substitution was located in the homeodomain (figure 2). $\mathrm{The} \mathrm{Ka} / \mathrm{Ks}$ ratio is significantly larger than one $(\mathrm{P}<0.01$, one-tailed $\mathrm{Z}$ test) [37], again supporting the hypothesis of strong positive selection on the RHOXF2 homeodomain during the evolution of humans and chimpanzees.

In Old World monkeys, RHOXF2 were duplicated twice independently, one in the leaf monkey lineage and the other in the macaque lineage (in the common ancestor of rhesus macaques and pig-tailed macaques). Theoretically,

Table 2 Comparison of sequence substitution rates of RHOXF1 and RHOXF2 in primates

\begin{tabular}{lllllll}
\hline & \multicolumn{3}{l}{ Human lineage } & \multicolumn{3}{l}{ Non-human primates lineage } \\
\cline { 2 - 7 } & lineage & N/S & Ka/Ks & lineage & N/S & Ka/Ks \\
\hline \multirow{6}{*}{ RHOXF2 } & A-HUM & $5 / 1$ & 1.01 & A-CHP & $11 / 0$ & $\infty$ \\
& B-HUM & $9 / 1$ & 1.99 & B-GOR & $6 / 4$ & 0.72 \\
& C-HUM & $22 / 3$ & $2.60^{*}$ & C-ORA & $9 / 7$ & 0.61 \\
& D-HUM & $27 / 5$ & 2.18 & D-SIA & $19 / 6$ & 1.59 \\
& E-HUM & $33 / 7$ & 1.24 & E-RM & $22 / 11$ & 0.96 \\
\hline \multirow{3}{*}{ RHOXF1 } & A-HUM & $0 / 3$ & 0 & A-CHP & $5 / 1$ & 1.52 \\
& B-HUM & $1 / 3$ & 0.10 & B-GOR & $5 / 3$ & 0.50 \\
& C-HUM & $6 / 4$ & 0.44 & C-ORA & $4 / 3$ & 0.38 \\
& E-HUM & $14 / 5$ & 0.83 & E-RM & $13 / 1$ & 3.87 \\
\hline
\end{tabular}

Note: A-E are the inferred ancestral nodes of the primate phylogenetic tree (figure 2). N/S indicates the number of non-synonymous substitutions and the number of synonymous substitutions of each lineage. ${ }^{*} \mathrm{Ka} / \mathrm{Ks}>1, \mathrm{P}=0.026(\mathrm{Z}$ test) it is also possible that there have been three copy loss events (the ancestor of DL and YGM, the RG lineage, and the ancestor of STM, AM and PDM) which can explain the observed pattern although it is less parsimonious than the proposed two independent duplications. Strong positive selection was detected in the Yunnan snub-nosed monkey lineage as well as in the lineage including rhesus and pig-tailed macaques (figure 2). Taken together, during the evolution of primates, along with parallel gene duplications and/or losses, positive selection has been acting on multiple primate lineages leading to the rapid protein sequence changes of RHOXF2.

\section{Expression pattern of RHOXF2 in primates}

To exam the expression pattern of RHOXF2 in primates, we performed real-time qPCR in four primate species (rhesus macaques, the white-browed gibbon, chimpanzee and humans). The general expression patterns in human, chimpanzee and gibbon are similar, consistent with the reported data in human and mice $[15,39]$, in which RHOXF2 is preferentially expressed in the testis (figure 5). However, the rhesus macaque showed a very different expression pattern. RHOXF2 is expressed in all the major tissues, but the highest expression was observed in the lung instead of the testicle (figure 5). This was further confirmed by testing two more individuals (one 2 yr male and one 2 yr female) (see additional file 9). The functional implication of the preferential expression of RHOXF2 in the lung of rhesus macaque is yet to be dissected.

It is noteworthy that we also observed expression of RHOXF2 in the brain. In humans, RHOXF2 is weakly expressed in the brain compared with the testis, and there are between-individual and between-developmental-stage variations (figure 5). In Wayne et al. (2002), the brain expression of RHOXF2 was not detected, which was likely due to the insensitive technology (Northern blot) used. RHOXF2 is also expressed in the brains of chimpanzee, gibbon and rhesus macaque.

To examine the expression of individual RHOXF2 paralog, we cloned and sequenced cDNAs of the two RHOXF2 copies in humans, and screened 7 adult human testicle samples and 4 human brain samples. We found that both copies are almost equally expressed in all testicle samples (clone counting, 20:17; see additional file 3), implying that the two copies are functionally redundant in the human testis. However, in the human brain, the expression pattern is different. In the embryo and new born brains, both copies are expressed (clone counting, 34:20; see additional file 3), while only one copy is expressed in adult brains (clone counting, 35:0; see additional file 3), suggesting tissue and developmental stage related expression divergence of the two RHOXF2 copies during human evolution. 
Table 3 The distribution of amino acid variations of RHOXF2 in human populations

\begin{tabular}{llllll}
\hline & \multicolumn{5}{c}{ Allele frequency } \\
\cline { 2 - 6 } polymorphic site & African $(\mathbf{n}=\mathbf{3 2})$ & European $(\mathbf{n}=\mathbf{2 1})$ & Melanesian $(\mathbf{n}=\mathbf{1 0})$ & East Asian $(\mathbf{n}=\mathbf{4 8})$ & Total $(\mathbf{n}=\mathbf{1 1 1})$ \\
\hline $83 \mathrm{Ala} \rightarrow$ Thr & 0.0179 & 0 & 0 & 0 & 0.0047 \\
$93 \mathrm{Asn} \rightarrow$ Asp & 0.5 & 0.643 & 0.750 & 0.723 & 0.660 \\
$151 \mathrm{Arg} \rightarrow$ Cys & 0.15 & 0.143 & 0.250 & 0.170 & 0.167 \\
$151 \mathrm{Arg} \rightarrow$ His & 0.0333 & 0 & 0 & 0 & 0.0093 \\
$176 \mathrm{Leu} \rightarrow$ Phe & 0 & 0 & 0 & 0.052 & 0.0096 \\
$209 \mathrm{Gln} \rightarrow$ His & 0.161 & 0.177 & 0 & 0.022 & 0.078 \\
$235 \mathrm{Gly} \rightarrow$ Asp & 0.887 & 0.972 & 0.778 & 0.696 & 0.808 \\
286 Pro $\rightarrow$ Leu & 0.0968 & 0 & 0.050 & 0 & 0.0333 \\
\hline
\end{tabular}

Note: The ancestral alleles in humans were determined by comparing with the non-human primate species. The frequencies shown are the derived alleles.

In the chimpanzee brain, we detected four cDNA sequences (clone counting, 34:45:4:1) and two of them are the major forms. One of the major forms (clone counting, 45) is a novel splice form that was not detected in the chimpanzee testis, however, this form produces a truncated protein. The other two minor forms likely represent background expression due to their truncated open-reading frames (see additional file 2 , additional file 3) and low expression levels. Interestingly, all four brain-expressed forms are from only one of the six gene copies in chimpanzee, suggesting between-copy expression divergence, similar to the pattern observed in the human brain. In the rhesus macaque, the expression pattern is similar among testicle,

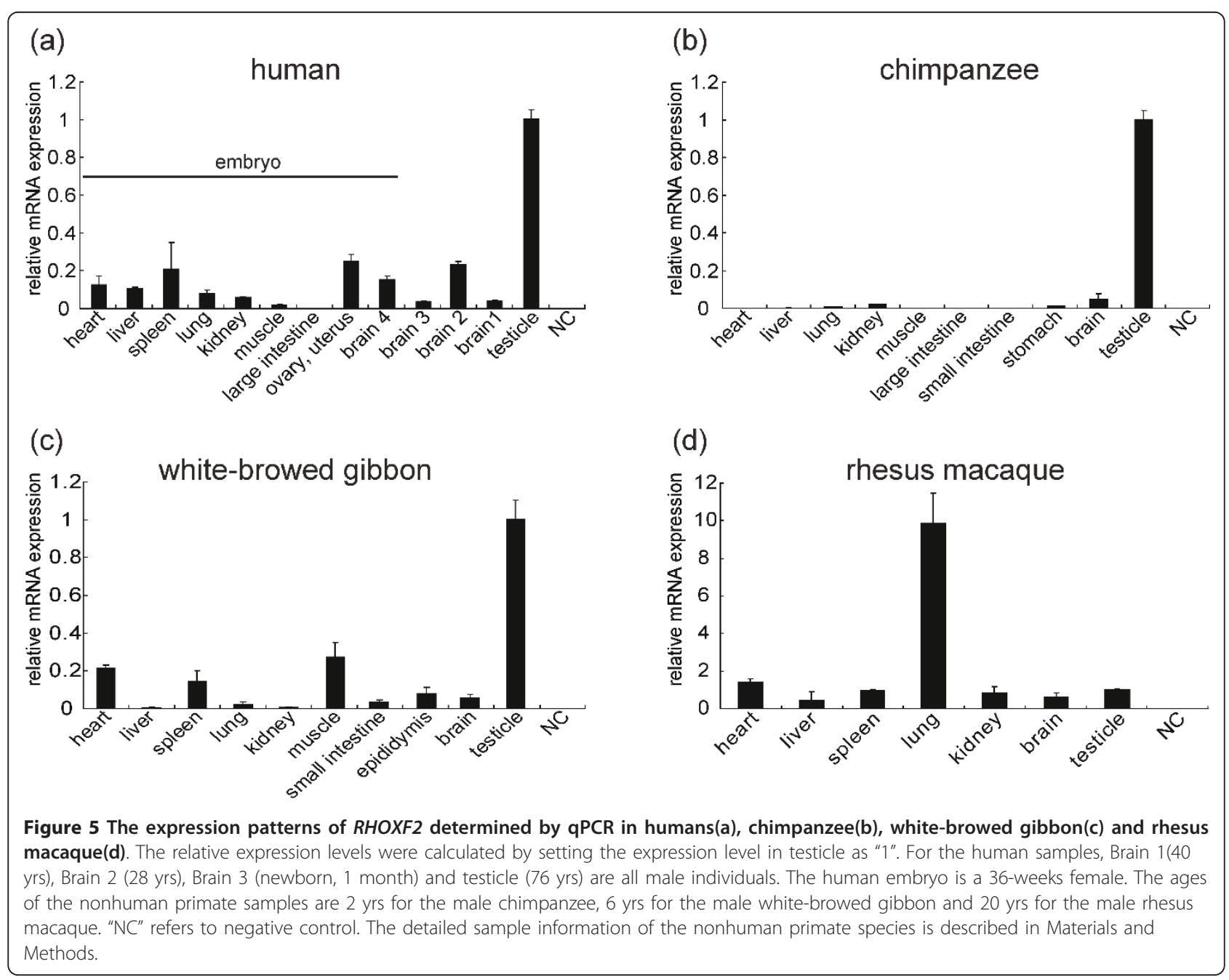


brain and lung, in which Copy-1 is preferentially expressed (clone counting, 59:7 for testicle, 41:3 for brain and 19:0 for lung; see additional file 3).

\section{Discussion}

We have presented a novel case of rapid evolution of an $\mathrm{X}$-linked homeobox gene in primates. Interestingly, unlike the few previously studied cases $[8-10,13,14]$, RHOXF2 also shows copy number variation among primate species. We showed that there had been parallel RHOXF2 duplications and/or losses along multiple primate lineages, which were likely mediated by the flanking ERVs. A similar gene duplication pattern was also observed for the mouse Rhox alpha subcluster paralogs [8-12], and gene loss was reported in the Hox gene cluster in nematode $[5,6]$.

RHOXF1 and RHOXF2 are the only members of the $R h o x$ family in primates [40]. Due to the rapid evolution of the Rhox family, RHOXF1 and RHOXF2 are highly divergent from their rodent orthologs. However, their functional roles in the reproductive system have been maintained in both rodents and primates. In the mouse, Rhox 5 is expressed in both male and female germ cells in developing fetal gonad [41,42]. In adults, it is expressed in the testis, epididymis and ovary $[43,44]$. The Rhox 5 null mice are subfertile, with defects in spermatozoa production and motility $[8,41]$. The mouse Rhox cluster has more than 30 genes with partially overlapping expression patterns, and plays partially redundant but distinct functional roles [8-10,18,45]. RHOXF1 and RHOXF2 in primates are functionally similar to Rhox5 in mouse. In the testis, both of them may down-regulate $U n c 5 c$ and Pltp expression, but only RHOXF2 can up-regulate Gdap1 expression [18]. During primate evolution, RHOXF1 was apparently highly conserved and likely maintains its original functional role in the reproductive system. In contrast, RHOXF2 has evolved rapidly leading to potential functional divergence in primates.

Darwinian positive selection is likely the key driving force leading to copy number variation, rapid amino acid changes as well as potential functional (e.g. gene expression pattern) divergence of RHOXF2 in primates. In several species, e.g. rhesus macaque and leaf monkeys, selection and lack of recombination have caused distinct sequence divergence between the two RHOXF2 copies within each species, which could lead to functional divergence. In humans, signals of rapid evolution and positive selection were also detected. However, due to frequent non-allelic recombinations, the two human copies have not clearly diverged. The situation in chimpanzees is much more complicated in which both rapid evolution and gene pseudolization might have occurred.

It has been shown that gene copy number and expression level are highly correlated [46]. For homeobox genes, due to their important roles in development, dosage changes may lead to functional consequences [47,48]. As the major function of RHOXF2 in primates is male reproduction, we speculate that the observed strong selection in multiple primate lineages is likely to be related to sperm competition in promiscuous mating systems $[49,50]$. Among the 17 primate species studied, four species showed strong signatures of positive selection (human, chimpanzee, Yunnan snub-nosed monkey and rhesus macaque), and all of them have promiscuous mating systems [51-57]. This pattern is also seen for the Rhox cluster in rodents [8].

In addition to its potential role in spermatogenesis, RHOXF2 may also be involved in the functioning of the nervous system. All the three down-stream genes directly regulated by RHOXF2, i.e. Unc5c [19,20], Pltp [21,22] and Gdap1 [23,24] also play important roles in the central nervous system. Hence, the brain expression of RHOXF2 in primates implies its possible involvement in brain function. In humans, only one of the two RHOXF2 copies is expressed in adult brains, and both copies are expressed equally in the brains of embryos and new-borns. This suggests a potential role of RHOXF2 in brain development [16-18]. Thus, it is likely that RHOXF2 may function in both the male reproductive system and the central nervous system through interactions with the down-stream genes. The question remains as to just how the expression of RHOXF2 is regulated in these different tissues.

It has been shown that the genome-wide gene expression patterns are similar between brain and testis in humans [58]. Interestingly, the human RHOXF2 protein down-regulates the expression of the Netrin-1 receptor, Unc5c [16-18], expressed in both brain and testis [16,59]. In the brain, the UNC5C protein level is mainly influenced by the Netrin-1 protein, which increases apoptosis of the UNC5C-expressing neurons $[60,61]$. In the testis, Unc5c prevents Sertoli cell from apoptosis and ensure sperm production [16]. A genome-wide analysis of cancer-testis (CT) gene expression showed that RHOXF2 is a CT gene with testis-selective expression [39]. Coincidentally, the CT genes are also expressed in a high percentage of human central nervous system tumors [62]. The potential functional role of RHOXF2 in the brain is likely the outcome of Darwinian positive selection which has driven the rapid evolution and functional divergence of RHOXF2 in primates, especially those species with more than one gene copies.

It is well known that brain evolution is not always positively associated with reproductive fitness [63]. A mutation with advantages for brain function may sometimes be detrimental to the reproductive system (and vice versa). Therefore, natural selection will result in a balance between the competing demands and advantages of brain and testis functions. As RHOXF2 may play a dual role 
acting in the testis and brain, it may have developed certain mechanism for balancing potential functional conflicts between reproduction and cognition. One potential molecular mechanism is the between-copy gene expression divergence, e.g. in human, both of the RHOXF2 copies are equally expressed in the testis, but only one copy is expressed in the adult brain. The potential functional divergence of different copies are yet to be elucidated by further studies in the future.

\section{Conclusions}

In summary, we provided an informative example of rapid evolution and copy number variation of an $\mathrm{X}$ linked homeobox gene (RHOXF2) in primates. Our sequence analysis indicates that parallel gene duplications/losses were likely to have been mediated by the flanking ERVs, and the rapid evolution of RHOXF2 had been driven by Darwinian positive selection on the male reproductive system and possibly also on the central nervous system, resulting in between-copy sequence and expression divergence among the primate species with more than one gene copy.

\section{Methods}

\section{Ethics statement}

All of the DNA samples used in this study were taken from collections by the Kunming Cell Bank of CAS, Kunming Blood Center and Shanghai National Genome Center in China. The research protocol was approved by the internal review board of Kunming Institute of Zoology, Chinese Academy of Sciences.

\section{Human and non-human primate DNA samples}

For DNA samples, a total of 111 human individuals from the major continental populations were sampled and sequenced, including 32 Africans, 21 Europeans, 10 Melanesians and 48 East Asians (Chinese and Cambodian). We also sampled 16 nonhuman primate species (10 Old World monkey species, 3 lesser ape species and 3 great ape species) reflecting a 25 million-year history of primate evolution (table 1). The sequences of a New World monkey species, white-tufted-ear marmoset (Callithrix jacchus) were obtained from the database (http:// genome.wustl.edu).

\section{Genomic DNA PCR, cloning and sequencing}

The coding region of the RHOXF2 gene (exon 1-4) was amplified by PCR and sequenced in humans and 16 nonhuman primate species. Universal primers for all species were designed based on published sequences of human and other primate species. The primer sequences are listed in additional file 10 . We first sequenced the PCR products directly. Then the PCR products were cloned into a pMD19-T vector using the T-vector kit
(Takara, Japan) and then transformed into E. coli DH5 $\alpha$. The individual clones were picked for sequencing. Sequencing was performed in both directions with the forward and reverse primers on an ABI-3130 automated sequencer.

\section{BAC library screening}

The pooled PCR-based method was used to screen a chimpanzee BAC library (CHORI251). According to the published sequences, the PCR primers were designed for BAC library screening. The best primer pairs were selected from the designed PCR primers through a series of pre-experiments. Primer sequences are shown in additional file 10 . The BAC end sequencing was performed for all the positive clones [64].

\section{RNA samples, reverse transcriptional PCR (RT PCR), cloning and sequencing}

We collected various organs (heart, liver, spleen, lung, kidney, muscle, intestine, pancreas, testicle and brain etc.) of three Chinese rhesus macaques (Macaca mulatta) (one male and one female 2 years old, and one male 20 years old), one white-browed gibbon (Hylobates hoolock) (male, 6 years old) and one chimpanzees (Pan troglodytes) (male, 2 years old). We also collected human brain samples from one new born male ( 1 month) and two adult males ( 28 years, 40 years), and multiple tissue samples from a female embryo (36 weeks). cDNAs from 2 rhesus macaque testis, 7 human testis, 2 chimpanzee testis were used for full length cDNA sequencing.

The total RNA samples were extracted with TRIzol (Invitrogen, Carlsbad, CA) following a standard protocol. They were treated with DNaseI (Takara, Tokyo, Japan) to remove possible genomic DNA contamination, then subject to reverse transcription using Omniscript Reverse Transcriptase (Qiagen, Valencia, CA) with oligo-dT primers (18 nucleotides), following the manufacturer's protocol. PCR was carried out at $95^{\circ} \mathrm{C}$ for $5 \mathrm{~min}$, and then at $95^{\circ} \mathrm{C}$ for $30 \mathrm{~s}, 59^{\circ} \mathrm{C}$ for $30 \mathrm{~s}$, and $72^{\circ} \mathrm{C}$ for $30 \mathrm{~s}$ (or $2 \mathrm{~min}$ ) for 35 cycles, and finally $72^{\circ} \mathrm{C}$ for $10 \mathrm{~min}$. The primer sequences are presented in additional file 10. Cloning and sequencing were performed as described for the genomic DNA PCR products.

\section{Gene copy number and expression level determination by real-time quantitative PCR}

The quantitative real-time PCR (qPCR) was performed using the SYBR premix ExTaq II (Takara, Tokyo, Japan) on a LightCycler 480 (Roche, Basel, Switzerland). For gene copy number estimation, the relative quantification method based on $\Delta \Delta \mathrm{Ct}$ was used to determine the relative copy numbers of the RHOXF2 gene in different species by comparison with a known single copy X-linked gene, transketolase-like 1 (TKTL1). The amplification 
efficiencies of RHOXF2 and TKTL1 in human and other non-human primates were tested and proven to be equal. PCR was carried out at $95^{\circ} \mathrm{C}$ for $4 \mathrm{~min}$, and then at $95^{\circ} \mathrm{C}$ for $20 \mathrm{~s}, 61^{\circ} \mathrm{C}$ for $20 \mathrm{~s}$ for 40 cycles. For humans, chimpanzees, gorillas, orangutans and gibbons, the primers sequences are: NM032498_RT_F AGGGCATCAATGGCAAGAAAC and NM032498_RT_R AGGC TGCTGGA ATGGCTGT; NM012253_RT_F TGGCAAT CTTTGA TGTGAACCG and NM012253_RT_R GGGG CAGGACAGAATGGAAAT. For the Old World monkeys, the primer pairs are: PEPP2-RT-owm-F AGAAGAGCCAAG TGGAGGAGACA and PEPP2-RT-owm-R GCAGTTACCATGACAGGCTGG; TKTL1-RT-owm-F CTACCGGGT GTTCTGCCTCAT and TKTL1-RT-owm-R AGATTGTC CAGACTGTAGTAGGAAGCA.

For measuring the gene expression levels, cDNA realtime PCRs were performed and the expression levels were determined by using glycerol-3-phosphate dehydrogenase (GAPDH) as the internal reference gene. PCR was carried out at $95^{\circ} \mathrm{C}$ for $2 \mathrm{~min}$, and then at $95^{\circ} \mathrm{C}$ for $10 \mathrm{~s}$, and $64^{\circ} \mathrm{C}$ for 20 s for 40 cycles. A variety of tissue types (heart, liver, spleen, lung, kidney, muscle, intestine, pancreas, testicle and brain etc.) were tested in Chinese rhesus macaques (one male and one female of 2 years old, and one male of 20 years old), white-browed gibbon (one 6 yrs male), chimpanzee (one 2 yrs male) and human (three brain samples, one testicle sample and multiple tissue samples from one female embryo). The GAPDH primers are identical in all four primate species: GAPDH_F ATTGCCCTCAACGACCACTTT and GAPDH_R GGTCTCTCTCTTCCT CTTGTGCTCT. The RHOXF2 primer pairs are: for humans, pepp2-HUM-QF1 CGTCCACGCCTTCACCCC and pepp2-HUM-QR1 GTCTCCTCCATTTGGCTCTTCTATT; for chimpanzees, PEPP2-cRT-chp-hum-F1 CGAGCAGTTC CCCAGTGAGTT and PEPP2-cRT-chp-R1 CCATTGATGCCCTCTGATGTCTC; for the white-browed gibbon, pepp2-GB-QF3 ACTACAGGATATGAA TGCT GCGGT and pepp2-GB-QR3 TGCTGCTTCT GTG CCTTGCT; For rhesus macaques, pepp2-RM-QF2 CAGGAGCTGGAGCGCATTTTC and pepp2-RM-QR2 CCTCCACTTGGCTCTTCTATTCTCA. The PCR product lengths are $164 \mathrm{bp}, 128 \mathrm{bp}, 100 \mathrm{bp}$ and $132 \mathrm{bp}$ respectively. The primer pairs are from different exons of RHOXF2 to avoid potential genomic DNA contamination. The list of the primers used is given in additional file 10 . For each tissue sample, one RNA extraction was prepared, and the qPCR was repeated three times.

\section{Fluorescence in situ hybridization (FISH)}

The positive BAC clone DNA was extracted according to the modified alkaline-lysis method. CHORI251-281C1 BAC clone DNA was labeled by Nick-translation with Biotin-dCTP (Invitrogen). The FISH method was described previously [64]. To eliminate the effect of cross- hybridization of common repeat sequences, the probes were blocked by using repetitive DNA (Cot) before hybridization. At least 10 independent metaphases or interphase nuclei were examined in determination of chromosomal band location.

\section{Data analysis}

Sequence data was edited and aligned using DNASTAR (DNASTAR, Inc.), then inspected and confirmed manually. The DNA haplotypes (or copies) of humans were inferred using PHASE [25]. The haplotypes of other nonhuman primates were determined by cloning and sequencing when more than two heterozygous sites were observed. For phylogenetic analysis, a neighbor joining (NJ) tree was constructed using MEGA4 [38]. Synonymous and non-synonymous substitution rates ( $K s$ and $\mathrm{Ka}$ ) were calculated using Pamilo-Bianchi-Li's method [65,66], and the one-tailed $Z$ test was used to detect deviation from neutrality [37,38]. Using PAML [36], the ancestral sequences of the internal nodes of the phylogenetic tree were inferred, and the substitution patterns were compared among different evolutionary lineages. Based on Yang's method [36], the selection model 2a (comparing with the neutral model 1a) was used to test positive selection in primates. Modified model A (thick lines in figure 2, i.e. the branches from the most recent common ancestor of Catarrhines to the human and chimpanzee lineages were taken as the foreground and compared with the corresponding null model with $\omega 2=$ 1 fixed) was used to test if there have been positive selections $(\mathrm{Ka} / \mathrm{Ks}>1)$ during the origins of humans and chimpanzees.

\section{Note \\ [GenBank: HQ283451- HQ283472]}

\section{Additional material}

Additional file 1: Table S1 The relative RHOXF2 gene copies
determined by qPCR in human population. Using TKTL1, an X-linked
single copy gene as control, the copy numbers were calculated by
setting one male individual with heterozygous sites (PG1302) as "2".
There are no RHOXF2 genomic DNA quantity difference between the
group without heterozygous sites and the group with heterozygous sites
(P = 0.12, T test).
Additional file 2: Figure S1 The coding DNA sequence alignment of
primate RHOXF2. The coding DNA sequences of chimpanzee are
denoted by schematic figures. Rhesus macaque (RM) CDS was inferred
from CDNA; Pig-tailed macaque (PTM), black leaf monkey (BLM) and grey
leaf monkey (GLM) CDSs were inferred from clone sequencing of
genomic DNA. ". indicates identical to the first sequence in each
alignment.
Additional file 3: Table S2 The cDNA clone counting of $R$ HOXF2. The
brain and testicle samples of human, chimpanzee and rhesus macaque
were included. The lung sample of rhesus macaque was also counted.
Brain 1 (40 yrs), brain 2 (28 yrs) and brain 3 (newborn, 1 month) are all
male individuals. Brain 4 was from a 36 weeks female embryo.


Additional file 4: Figure S2 FISH (Fluorescence In Situ Hybridization) analysis in human, chimpanzee and gorilla using the RHOXF2 probe. The red arrows indicate the positive signals.

Additional file 5: Figure S3 The ERV sequence alignment in human (hum), chimpanzee (CHP), gorilla (GOR), orangutan (ORA) and rhesus macaque (RM). ".' indicates identical to the first sequence in each alignment. '-' indicates an alignment gap.

Additional file 6: Figure S4. The phylogenetic tree showing sequence substitution pattern of each primate lineage. The numbers of nonsynonymous and synonymous substitutions (N/S) and the amino-acid insertions-deletions are labeled for each lineage. The sequences of of human and chimpanzee were reconstructed by excluding the withinspecies non-synonymous changes. Using marmoset sequence as outgroup, all internal node sequences were inferred by PAML. The lineages showing $\mathrm{Ka} / \mathrm{Ks}$ ratios significantly larger than one are denoted by ${ }^{\prime * \prime}(p<0.05)$ or ${ }^{* * *}$ $(p<0.01)$. For the abbreviations of the primate species, refer to table 1 .

Additional file 7: Figure S5 Protein sequence alignment of primate RHOXF2. ". indicates identical to the first sequence in each alignment. '-' indicates an alignment gap and '*' indicates a stop codon. The homeodomain region and proline-rich domain region are underlined. HUM-1/HUM-2 and CHP-1/CHP-2 represent the polymorphic sites in populations and the sequence difference among the within-species copies. The ancestral amino acid 151R is still in human population besides $151 \mathrm{H}$ and $151 \mathrm{C}$. For the abbreviations of the primate species names, refer to table 1 .

Additional file 8: Table S3 The pairwise $\mathrm{Ka} / \mathrm{Ks}$ ratios of $R H O X F 2$ in the primate species tested. The Ka/Ks ratios were estimated following Pamilo-Bianchi-Li's method.

Additional file 9: Figure S6 The expression pattern of RHOXF2 determined by qPCR in two extra rhesus macaque individuals. (a) a 2 yr male; (b) a 2 yr female. The relative expression levels were calculated by setting the value in the testicle as " 1 ". The result is consistent with the data presented in Figure 5 .

Additional file 10: Table S4 The primer sequences of PCR and sequencing in this study.

\section{Acknowledgements}

This work was supported by the National 973 program of China [grant numbers 2011CBA00401, 2007CB947701]; the National Natural Science Foundation of China [grant number 30871343]; and the Natural Science Foundation of Yunnan Province of China [grant number Y003721111].We are thankful to the technical help of Xiao-na Fan, Hui Zhang and Yi-chuan Yu. We thank Dr. Phillip Kaitovich for providing the testis CDNA sample of chimpanzee. We also thank Dr. Darren Curnoe for this critical reading of the manuscript.

\section{Author details}

'State Key Laboratory of Genetic Resources and Evolution, Kunming Institute of Zoology and Kunming Primate Research Center, Chinese Academy of Sciences, Kunming, Yunnan 650223, China. ${ }^{2}$ Graduate School of the Chinese Academy of Sciences, Beijing 100039, China. ${ }^{3}$ Department of Internal Medicine, Renal Division, Washington University School of Medicine, St. Louis, MO 63110, USA

\section{Authors' contributions}

$B S$, YQW and ALN conceived and designed the experiments. ALN, YOW, JC, CHL, JKW, RZ and HZ performed the experiments. YQW and ALN analyzed the data. BS, YQW and ALN wrote the paper. All authors read and approved the final manuscript.

Received: 6 April 2011 Accepted: 12 October 2011

Published: 12 October 2011

\section{References}

1. Gehring WJ, Affolter M, Burglin T: Homeodomain proteins. Annu Rev Biochem 1994, 63:487-526.
2. McGinnis W, Hart CP, Gehring WJ, Ruddle FH: Molecular cloning and chromosome mapping of a mouse DNA sequence homologous to homeotic genes of Drosophila. Cell 1984, 38(3):675-680.

3. Zhang J, Nei M: Evolution of Antennapedia-class homeobox genes. Genetics 1996, 142(1):295-303.

4. Ting CT, Tsaur SC, Wu ML, Wu Cl: A rapidly evolving homeobox at the site of a hybrid sterility gene. Science 1998, 282(5393):1501-1504

5. Aboobaker AA, Blaxter ML: Hox Gene Loss during Dynamic Evolution of the Nematode Cluster. Curr Biol 2003, 13(1):37-40.

6. Aboobaker A, Blaxter M: Hox gene evolution in nematodes: novelty conserved. Curr Opin Genet Dev 2003, 13(6):593-598.

7. Sutton KA, Wilkinson MF: Rapid evolution of a homeodomain: evidence for positive selection. J Mol Evol 1997, 45(6):579-588.

8. Maclean JA, Chen MA, Wayne CM, Bruce SR, Rao M, Meistrich ML, Macleod C, Wilkinson MF: Rhox: a new homeobox gene cluster. Cell 2005, 120(3):369-382.

9. MacLean JA, Lorenzetti D, Hu Z, Salerno WJ, Miller J, Wilkinson MF: Rhox homeobox gene cluster: recent duplication of three family members. Genesis 2006, 44(3):122-129.

10. Wang $X$, Zhang J: Remarkable expansions of an X-linked reproductive homeobox gene cluster in rodent evolution. Genomics 2006, 88(1):34-43

11. Morris L, Gordon J, Blackburn CC: Identification of a tandem duplicated array in the Rhox alpha locus on mouse chromosome X. Mamm Genome 2006, 17(2):178-187.

12. Jackson M, Watt AJ, Gautier P, Gilchrist D, Driehaus J, Graham GJ, Keebler J, Prugnolle F, Awadalla P, Forrester LM: A murine specific expansion of the Rhox cluster involved in embryonic stem cell biology is under natural selection. BMC Genomics 2006, 7:212.

13. Wang $X$, Zhang J: Rapid evolution of mammalian X-linked testisexpressed homeobox genes. Genetics 2004, 167(2):879-888.

14. Wang X, Zhang J: Rapid evolution of primate ESX1, an X-linked placentaand testis-expressed homeobox gene. Hum Mol Genet 2007, 16(17):2053-2060.

15. Wayne CM, MacLean JA, Cornwall G, Wilkinson MF: Two novel human Xlinked homeobox genes, hPEPP1 and hPEPP2, selectively expressed in the testis. Gene 2002, 301(1-2):1-11.

16. Hu Z, Shanker S, MacLean JA, Ackerman SL, Wilkinson MF: The RHOX5 homeodomain protein mediates transcriptional repression of the netrin1 receptor gene Unc5c. J Biol Chem 2008, 283(7):3866-3876.

17. Hu Z, MacLean JA, Bhardwaj A, Wilkinson MF: Regulation and function of the Rhox5 homeobox gene. Ann N Y Acad Sci 2007, 1120:72-83.

18. Hu Z, Dandekar D, O'Shaughnessy PJ, De Gendt K, Verhoeven G, Wilkinson MF: Androgen-induced Rhox homeobox genes modulate the expression of AR-regulated genes. Mol Endocrinol 2010, 24(1):60-75.

19. Round J, Stein E: Netrin signaling leading to directed growth cone steering. Curr Opin Neurobiol 2007, 17(1):15-21

20. Ackerman SL, Kozak LP, Przyborski SA, Rund LA, Boyer BB, Knowles BB: The mouse rostral cerebellar malformation gene encodes an UNC-5-like protein. Nature 1997, 386(6627):838-842.

21. Dong W, Albers JJ, Vuletic S: Phospholipid transfer protein reduces phosphorylation of tau in human neuronal cells. J Neurosci Res 2009 87(14):3176-3185.

22. Vuletic S, Peskind ER, Marcovina SM, Quinn JF, Cheung MC, Kennedy H, Kaye JA, Jin LW, Albers JJ: Reduced CSF PLTP activity in Alzheimer's disease and other neurologic diseases; PLTP induces ApoE secretion in primary human astrocytes in vitro. J Neurosci Res 2005, 80(3):406-413.

23. Liu H, Nakagawa T, Kanematsu T, Uchida T, Tsuji S: Isolation of 10 differentially expressed cDNAs in differentiated Neuro2a cells induced through controlled expression of the GD3 synthase gene. J Neurochem 1999, 72(5):1781-1790.

24. Cuesta A, Pedrola L, Sevilla T, Garcia-Planells J, Chumillas MJ, Mayordomo F, LeGuern E, Marin I, Vilchez JJ, Palau F: The gene encoding gangliosideinduced differentiation-associated protein 1 is mutated in axonal Charcot-Marie-Tooth type 4A disease. Nat Genet 2002, 30(1):22-25.

25. Stephens M, Smith NJ, Donnelly P: A new statistical method for haplotype reconstruction from population data. Am J Hum Genet 2001, 68(4):978-989.

26. Andersson AC, Yun Z, Sperber GO, Larsson E, Blomberg J: ERV3 and related sequences in humans: structure and RNA expression. J Virol 2005 79(14):9270-9284. 
27. Sun C, Skaletsky H, Rozen S, Gromoll J, Nieschlag E, Oates R, Page DC: Deletion of azoospermia factor a (AZFa) region of human $Y$ chromosome caused by recombination between HERV15 proviruses. Hum Mol Genet 2000, 9(15):2291-2296.

28. Bosch E, Jobling MA: Duplications of the AZFa region of the human $Y$ chromosome are mediated by homologous recombination between HERVs and are compatible with male fertility. Hum Mol Genet 2003, 12(3):341-347

29. Kamp C, Hirschmann P, Voss H, Huellen K, Vogt PH: Two long homologous retroviral sequence blocks in proximal Yq11 cause AZFa microdeletions as a result of intrachromosomal recombination events. Hum Mol Genet 2000, 9(17):2563-2572

30. Bosch E, Hurles ME, Navarro A, Jobling MA: Dynamics of a human interparalog gene conversion hotspot. Genome Res 2004, 14(5):835-844.

31. Redon R, Ishikawa S, Fitch KR, Feuk L, Perry GH, Andrews TD, Fiegler $H$, Shapero MH, Carson AR, Chen W, et al: Global variation in copy number in the human genome. Nature 2006, 444(7118):444-454.

32. Perry GH, Ben-Dor A, Tsalenko A, Sampas N, Rodriguez-Revenga L, Tran CW Scheffer A, Steinfeld I, Tsang P, Yamada NA, et al: The Fine-Scale and Complex Architecture of Human Copy-Number Variation. The American Journal of Human Genetics 2008, 82(3):685-695.

33. Fujitani $Y$, Kobayashi I: Effect of DNA sequence divergence on homologous recombination as analyzed by a random-walk model. Genetics 1999, 153(4):1973-1988.

34. Opperman R, Emmanuel E, Levy AA: The effect of sequence divergence on recombination between direct repeats in Arabidopsis. Genetics 2004, 168(4):2207-2215.

35. Chen FC, Li WH: Genomic divergences between humans and other hominoids and the effective population size of the common ancestor of humans and chimpanzees. Am J Hum Genet 2001, 68(2):444-456.

36. Yang Z: PAML: a program package for phylogenetic analysis by maximum likelihood. Comput Appl Biosci 1997, 13(5):555-556.

37. Kumar S, Tamura K, Jakobsen IB, Nei M: MEGA2: molecular evolutionary genetics analysis software. Bioinformatics 2001, 17(12):1244-1245.

38. Tamura K, Dudley J, Nei M, Kumar S: MEGA4: Molecular Evolutionary Genetics Analysis (MEGA) software version 4.0. Mol Biol Evol 2007 24(8):1596-1599.

39. Hofmann O, Caballero OL, Stevenson BJ, Chen YT, Cohen T, Chua R, Maher CA, Panji S, Schaefer U, Kruger A, et al: Genome-wide analysis of cancer/testis gene expression. Proc Natl Acad Sci USA 2008, 105(51):20422-20427

40. Holland PW, Booth HA, Bruford EA: Classification and nomenclature of all human homeobox genes. BMC Biol 2007, 5:47.

41. Pitman JL, Lin TP, Kleeman JE, Erickson GF, MacLeod CL: Normal reproductive and macrophage function in Pem homeobox genedeficient mice. Dev Biol 1998, 202(2):196-214.

42. Daggag $H$, Svingen $T$, Western PS, van den Bergen JA, McClive $P J$ Harley VR, Koopman P, Sinclair AH: The rhox homeobox gene family shows sexually dimorphic and dynamic expression during mouse embryonic gonad development. Biol Reprod 2008, 79(3):468-474.

43. Maiti S, Doskow J, Sutton K, Nhim RP, Lawlor DA, Levan K, Lindsey JS, Wilkinson MF: The Pem homeobox gene: rapid evolution of the homeodomain, $\mathrm{X}$ chromosomal localization, and expression in reproductive tissue. Genomics 1996, 34(3):304-316.

44. Lindsey JS, Wilkinson MF: Pem: a testosterone- and LH-regulated homeobox gene expressed in mouse Sertoli cells and epididymis. Dev Biol 1996, 179(2):471-484

45. MacLean JA, Wilkinson MF: The Rhox genes. Reproduction 2010

46. Jung SH, Shin SH, Yim SH, Choi HS, Lee SH, Chung YJ: Integrated analysis of copy number alteration and RNA expression profiles of cancer using a high-resolution whole-genome oligonucleotide array. Exp Mol Med 2009, 41(7):462-470.

47. Gage PJ, Suh H, Camper SA: Dosage requirement of Pitx2 for development of multiple organs. Development 1999, 126(20):4643-4651.

48. Liu YH, Tang Z, Kundu RK, Wu L, Luo W, Zhu D, Sangiorgi F, Snead ML, Maxson RE: Msx2 gene dosage influences the number of proliferative osteogenic cells in growth centers of the developing murine skull: a possible mechanism for MSX2-mediated craniosynostosis in humans. Dev Biol 1999, 205(2):260-274

49. Anderson MJ, Chapman SJ, Videan EN, Evans E, Fritz J, Stoinski TS, Dixson AF, Gagneux P: Functional evidence for differences in sperm competition in humans and chimpanzees. Am J Phys Anthropol 2007, 134(2):274-280.

50. Muller MN, Kahlenberg SM, Emery Thompson M, Wrangham RW: Male coercion and the costs of promiscuous mating for female chimpanzees. Proc Biol Sci 2007, 274(1612):1009-1014.

51. Ma SL, Wang YX, Jiang XL, Li JX: Study on the social behavior and habitual speciality of yunnan golden monkey. Acta Theriologica Sinica 1989, 9(3):161-167, (9).

52. Short RV: Sexual selection and its component parts, somatic and genital selection, as illustrated by man and the great apes. Adv Study Behav 1979, 9:131-158.

53. Harcourt AH, Harvey PH, Larson SG, Short RV: Testis weight, body weight and breeding system in primates. Nature 1981, 293(5827):55-57.

54. Harcourt AH, Purvis A, Liles L: Sperm competition: mating system, not breeding system, affects testes size of primates. Funct Ecol 1995, 9:468-476

55. Dixson AF, Anderson MJ: Sexual behavior, reproductive physiology and sperm competition in male mammals. Physiol Behav 2004, 83(2):361-371.

56. Cui LW, Huo S, Zhong T, Xiang ZF, Xiao W, Quan RC: Social organization of black-and-white snub-nosed monkeys (Rhinopithecus bieti) at Deqin, China. Am J Primatol 2008, 70(2):169-174.

57. Dixson AL, Anderson MJ: Sexual selection, seminal coagulation and copulatory plug formation in primates. Folia Primatol (Basel) 2002, 73(23):63-69.

58. Guo J, Zhu P, Wu C, Yu L, Zhao S, Gu X: In silico analysis indicates a similar gene expression pattern between human brain and testis. Cytogenet Genome Res 2003, 103(1-2):58-62.

59. Ackerman SL, Knowles BB: Cloning and mapping of the UNC5C gene to human chromosome 4q21-q23. Genomics 1998, 52(2):205-208.

60. Serafini T, Colamarino SA, Leonardo ED, Wang $H$, Beddington $R$, Skarnes WC, Tessier-Lavigne M: Netrin-1 is required for commissural axon guidance in the developing vertebrate nervous system. Cell 1996, 87(6):1001-1014

61. Yee KT, Simon HH, Tessier-Lavigne M, O'Leary DM: Extension of long leading processes and neuronal migration in the mammalian brain directed by the chemoattractant netrin-1. Neuron 1999, 24(3):607-622.

62. Lee MH, Son El, Kim E, Kim IS, Yim MB, Kim SP: Expression of cancer-testis genes in brain tumors. J Korean Neurosurg Soc 2008, 43(4):190-193.

63. Schillaci MA: Primate mating systems and the evolution of neocortex size. Journal of Mammalogy 2008, 89(1):58-63.

64. Xu HL, Qian YP, Nie WH, Chi JX, Yang FT, Su B: Construction, characterization and chromosomal mapping of bacterial artificial chromosome (BAC) library of Yunnan snub-nosed monkey (Rhinopithecus bieti). Chromosome Res 2004, 12(3):251-262.

65. Li WH: Unbiased estimation of the rates of synonymous and nonsynonymous substitution. J Mol Evol 1993, 36(1):96-99.

66. Pamilo P, Bianchi NO: Evolution of the Zfx and Zfy genes: rates and interdependence between the genes. Mol Biol Evol 1993, 10(2):271-281.

doi:10.1186/1471-2148-11-298

Cite this article as: Niu et al:: Rapid evolution and copy number variation of primate RHOXF2, an X-linked homeobox gene involved in male reproduction and possibly brain function. BMC Evolutionary Biology 2011 11:298.

\section{Submit your next manuscript to BioMed Central and take full advantage of:}

- Convenient online submission

- Thorough peer review

- No space constraints or color figure charges

- Immediate publication on acceptance

- Inclusion in PubMed, CAS, Scopus and Google Scholar

- Research which is freely available for redistribution

Submit your manuscript at www.biomedcentral.com/submit
C Biomed Central 